\title{
Alpine soil carbon is vulnerable to rapid microbial decomposition under climate cooling
}

\author{
Linwei $\mathrm{Wu}^{1,2,11}$, Yunfeng Yang ${ }^{1,11}$, Shiping Wang ${ }^{3,4}$, Haowei Yue ${ }^{1}$, Qiaoyan Lin $^{5}$, \\ Yigang $\mathrm{Hu}^{5,6}$, Zhili $\mathrm{He}^{2}$, Joy D Van Nostrand ${ }^{2}$, Lauren Hale ${ }^{2}$, Xiangzhen Li ${ }^{7}$, Jack A Gilbert ${ }^{8,9}$ \\ and Jizhong Zhou ${ }^{1,2,10}$ \\ ${ }^{1}$ State Key Joint Laboratory of Environment Simulation and Pollution Control, School of Environment, \\ Tsinghua University, Beijing, China: ${ }^{2}$ Institute for Environmental Genomics, Department of Microbiology and \\ Plant Biology, and School of Civil Engineering and Environmental Sciences, University of Oklahoma, \\ Norman, OK, USA; ${ }^{3}$ Key Laboratory of Alpine Ecology and Biodiversity, Institute of Tibetan Plateau Research, \\ Chinese Academy of Sciences, Beijing, China; ${ }^{4}$ CAS Center for Excellence in Tibetan Plateau Earth Science, \\ Beijing, China; ${ }^{5}$ Key Laboratory of Adaption and Evolution of Plateau Biota, Northwest Institute of Plateau \\ Biology, Chinese Academy of Sciences, Xining, China; ${ }^{6}$ Shapotou Desert Experiment and Research Station, \\ Cold and Arid Regions and Environmental \& Engineering Research Institute, Chinese Academy of Sciences, \\ Lanzhou, China; ${ }^{7}$ Chengdu Institute of Biology, Chinese Academy of Sciences, Chengdu, China; ${ }^{8}$ The \\ Microbiome Center, BioScience Division, Argonne National Laboratory, Argonne, IL, USA; ${ }^{9}$ Department of \\ Surgery, University of Chicago, Chicago, IL, USA and ${ }^{10}$ Earth and Environmental Sciences, Lawrence Berkeley \\ National Laboratory, Berkeley, CA, USA
}

\begin{abstract}
As climate cooling is increasingly regarded as important natural variability of long-term global warming trends, there is a resurging interest in understanding its impact on biodiversity and ecosystem functioning. Here, we report a soil transplant experiment from lower to higher elevations in a Tibetan alpine grassland to simulate the impact of cooling on ecosystem community structure and function. Three years of cooling resulted in reduced plant productivity and microbial functional potential (for example, carbon respiration and nutrient cycling). Microbial genetic markers associated with chemically recalcitrant carbon decomposition remained unchanged despite a decrease in genes associated with chemically labile carbon decomposition. As a consequence, cooling-associated changes correlated with a decrease in soil organic carbon (SOC). Extrapolation of these results suggests that for every $1^{\circ} \mathrm{C}$ decrease in annual average air temperature, $0.1 \mathrm{Pg}(0.3 \%)$ of SOC would be lost from the Tibetan plateau. These results demonstrate that microbial feedbacks to cooling have the potential to differentially impact chemically labile and recalcitrant carbon turnover, which could lead to strong, adverse consequences on soil $\mathrm{C}$ storage. Our findings are alarming, considering the frequency of short-term cooling and its scale to disrupt ecosystems and biogeochemical cycling. The ISME Journal (2017) 11, 2102-2111; doi:10.1038/ismej.2017.75; published online 23 May 2017
\end{abstract}

\section{Introduction}

Global climate change science has predominantly targeted climate warming (Luo, 2007; Frey et al., 2013; Nie et al., 2013), but this focus is changing, as it is increasingly recognized that temporary, local cooling events are common amidst long-term global warming trends (Alley et al., 2003; Ji et al., 2014). There has been significant cooling in the Antarctic

Correspondence: Y Yang, State Key Joint Laboratory of Environment Simulation and Pollution Control, School of Environment, Tsinghua University, 1 Tsinghua Garden Road, Haidian District, Beijing 100084, China.

E-mail: yangyf@tsinghua.edu.cn

${ }^{11}$ These authors contributed equally to this work.

Received 27 September 2016; revised 14 March 2017; accepted 23 March 2017; published online 23 May 2017
Peninsula as the late 1990s, arising from natural variability of the regional atmospheric circulation (Turner et al., 2016). It has been projected that the climate in the 21st century is likely to produce periods as long as one or two decade(s) of cooling (Easterling and Wehner, 2009; Lyubushin and Klyashtorin, 2012), which is alarming because historic evidence shows that cooling may perturb ecosystems and biogeochemical cycling at a scale comparable to what is known for warming (McAnena et al., 2013). For instance, cooling on the Antarctic continent between 1966 and 2000 led to a rapid decrease in the primary productivity of lakes (6-9\% per year) as well as the number of soil invertebrates (more than 10\% loss per year) (Doran et al., 2002). Therefore, further understanding of the full range of possible climate change scenarios and 
their potential impacts is of considerable value for policy makers and citizens to promulgate effective responses. Despite the impact, we still lack a fundamental understanding of how ecosystems respond to climate cooling.

To date, the effects of cooling are estimated indirectly by historical records (Campbell and McAndrews, 1993; Doran et al., 2002) or model simulation (Lucht et al., 2002), owing to the difficulty of carrying out in situ studies. Soil transplant experiments provide an opportunity to quantify the direct influence of substantial climate changes on the plant and soil microbial community structure and function (Breeuwer et al., 2010; Vanhala et al., 2011; Luan et al., 2014). For example, soil transplants into warmer climates have shown comparable results to long-term in situ artificial warming (Petchey et al., 1999; Vanhala et al., 2011; Zhou et al., 2012; Luan et al., 2014; Yue et al., 2015). In this study, we conducted a soil transplant study in a Tibetan alpine grassland, which is the largest grassland on the Eurasian continent (Yang et al., 2008). Soils on the Tibetan alpine store a large amount of organic C (about $10 \%$ of the terrestrial $\mathrm{C}$ in China) and are especially vulnerable to global climate change (Qiu, 2008; Yang et al., 2008), making it an ideal region to study the feedback of the grassland ecosystem to climate change. In this study, soils with attached vegetation from lower elevations were moved sequentially to higher elevations, along an elevation gradient of 3200, 3400, 3600 and $3800 \mathrm{~m}$ above sea level (see Materials and Methods for details). Soils mock transplanted, that is, soils removed from and then reinstalled to the same place, were used as controls. Various theoretical and empirical studies have suggested that climate warming increases both plant productivity and soil respiration (Luo, 2007; Zhou et al., 2012), resulting in an increase in organic $C$ loss through increased soil respiration, which is not offset by increased net primary production (Frey et al., 2013). Therefore, we hypothesize that, in contrast to warming, cooling would suppress associated ecosystem functional processes, such as $\mathrm{C}$ uptake and respiration, and consequently cause a net increase in SOC.

\section{Materials and Methods}

\section{Experimental design and soil sampling}

The transplant experiments were carried out in Haibei Alpine Meadow Ecosystem Research Station $\left(37^{\circ} 37^{\prime} \mathrm{N}, 101^{\circ} 12^{\prime} \mathrm{E}\right)$ of the Northeastern Tibet Plateau, Qinghai, China. Experimental plots were set up in May 2007. Along an elevation gradient of 3200, 3400, 3600 and $3800 \mathrm{~m}$ above sea level, triplicate soils with sizes of $1 \mathrm{~m}$ length $\times 1 \mathrm{~m}$ width $\times 0.3 \mathrm{~m}$ depth were dug out from the ground, with soil and aboveground vegetation intact, and transplanted upwards to plots at higher elevations. This strategy resulted in 18 transplanted samples (namely,
3200T3400, 3200T3600, 3200T3800, 3400T3600, $3400 \mathrm{~T} 3800$ and $3600 \mathrm{~T} 3800$, which means $3200 \mathrm{~m}$ plots to $3400 \mathrm{~m}$ plots, and so on). To simulate the disturbance effect due to soil extraction, triplicate plots at the elevations of 3200,3400 and $3600 \mathrm{~m}$ were mock transplanted and reestablished in place to serve as controls, that is, they were dug out from the ground but put back to the original plots. All plots were randomized in block design, and surrounded by plastic to minimize exchange with neighboring soils.

Soil samples were collected in August 2009 and used for 454 pyrosequencing of $16 \mathrm{~S}$ rRNA gene amplicon, GeoChip 4.0 (Tu et al., 2014) and environmental variable measurements. Three soil cores with a diameter of $1.5 \mathrm{~cm}$ at the depth of $0-20 \mathrm{~cm}$ were taken randomly from each plot. Then soil samples were transported back to the laboratory at $4{ }^{\circ} \mathrm{C}$ in cooler boxes and sieved with a $2 \mathrm{~mm}$ mesh to remove visible grassroots and stones. Soil samples for pyrosequencing and GeoChip experiments were kept at $-80^{\circ} \mathrm{C}$ until DNA extraction, and soil samples for environmental variable measurements were kept at $4^{\circ} \mathrm{C}$.

\section{Environmental variable measurements}

Vegetation variables were measured for a sub-plot within each plot. Vegetation species, density, biomass and average height were recorded using established protocols (Klein et al., 2007) when soils were sampled. Soil temperature was measured at depths of 5 and $20 \mathrm{~cm}$ using type-K thermocouples (Campbell Scientific, Logan, Utah, USA) coupled to a CR1000 datalogger, while soil moisture was recorded every $30 \mathrm{~min}$ at depths of 5 and $10 \mathrm{~cm}$ with time domain reflectometry (TDR) (Model Diviner-2000, Sentek Pty Ltd., Australia). Soil biogeochemical variables were measured as previously described (Yang et al., 2014). In brief, total organic C (TOC) and total $\mathrm{N}$ (TN) were measured by a TOC-5000 A analyzer (Shimadzu Corp., Kyoto, Japan) and a Vario EL III Elemental Analyzer (Elementar, Hanau, Germany) using standard protocols (Ryba and Burgess, 2002). Soil $\mathrm{NH}_{4}^{+}-\mathrm{N}$ and $\mathrm{NO}_{3}-\mathrm{N}$ were analyzed with a FIAstar 5000 Analyzer (FOSS, Hillerd, Danmark). The soil C/N ratio was calculated as the TOC to TN ratio.

SOC density can be estimated using TOC and soil bulk density values (Yang et al., 2009). SOC density in the top $20 \mathrm{~cm}$ was calculated as follows:

$\mathrm{SOC}=\sum_{i=1}^{n} T_{i} \times \mathrm{BD}_{i} \times \mathrm{TOC}_{i} \times\left(1-C_{i}\right) / 100$

where SOC, $T_{i}, \mathrm{BD}_{i}, \mathrm{TOC}_{i}$ and $C_{i}$ represent SOC density $\left(\mathrm{kg} \mathrm{C} \mathrm{m}^{-2}\right)$, layer thickness (cm), bulk density $\left(\mathrm{g} \mathrm{cm}^{-3}\right)$, TOC $\left(\mathrm{g} \mathrm{kg}^{-1}\right)$ and percentage of the fraction $>2 \mathrm{~mm}$ of the $i$ th soil layer, respectively. 
Ecosystem respiration (Re) and $\mathrm{CH}_{4}, \mathrm{~N}_{2} \mathrm{O}$ flux estimation

During the growing seasons, the Re was measured by opaque, static, manual stainless steel chambers (Lin et al., 2011) every 7-10 days at 9:00 to 11:00 am from May to September, depending on weather conditions. Based on previous experiments, the measurements obtained between 9:00 and 11:00 am best represented the average daily $\mathrm{CO}_{2}$ flux (Lin et al., 2011). The chambers were of the same architecture and dimension $(40 \mathrm{~cm} \times 40 \mathrm{~cm} \times 40 \mathrm{~cm})$ as previously described (Ma et al., 2006). Chambers were closed for half an hour and gas samples $(100 \mathrm{ml})$ were collected every $10 \mathrm{~min}$ using plastic syringes. The $\mathrm{CO}_{2}, \mathrm{CH}_{4}$ and $\mathrm{N}_{2} \mathrm{O}$ concentrations of gas samples were analyzed with a gas chromatograph (HP Series 4890D, Hewlett Packard, USA) within 24 h after gas sampling. The gas chromatograph configurations for analyzing gas concentrations and the methods for calculating gas flux were previously described (Song et al., 2003). The average gas flux in August 2009, when soil samples were collected, was used for statistical analyses in this study.

DNA extraction, 454 pyrosequencing and GeoChip 4.0 experiments

DNA extraction, purification, pyrosequencing and GeoChip 4.0 experiments, and raw data processing methods were described in recent studies (Rui et al., 2015; Yue et al., 2015). While GeoChip experiments were conducted for all samples, pyrosequencing experiments were conducted in most samples except for 3600 and 3600T3800 samples, which cannot be made up due to the lack of DNA from them for sequencing. However, the missing samples did not considerably affect our results. In brief, the Fast DNA Spin kit (MP Biomedical, Carlsbad, CA, USA) was used to extract DNA from $0.5 \mathrm{~g}$ soil, following the manufacturer's instructions. The V4-V5 hypervariable regions of $16 \mathrm{~S}$ rRNA genes were PCR amplified with primers 515F (5'-GTGYCAGCMGCCGCGGTA $\left.-3^{\prime}\right)$ and 909R (5'-CCCCGYCAATTCMTTTRAGT-3'). The pyrosesequencing experiments were conducted with a GS FLX system (454 Life Sciences, Branford, CT, USA). The raw sequences were trimmed for quality control using the RDP Pipeline Initial Process (http://pyro.cme.msu.edu/). Sequences with low quality (length $<300 \mathrm{bp}$, with ambiguous base ' $\mathrm{N}$ ', or average base quality score $<20$ ) were removed, resulting in 170161 high-quality and chimera-free reads with an average length of $408 \mathrm{bp}$. Then sequences were aligned using the Aware Infernal Aligner in the RDP pyrosequencing pipeline, and subjected to chimera check using the Uchime algorithm, and resampling to 2291 sequences per sample. Sequences were clustered by the completelinkage clustering method incorporated in the RDP platform. Operational taxonomic units were classified using a 97\% sequence identity cutoff and singletons were removed. Natural logarithmic transformation was used before statistical analyses. The GeoChip experiments were performed as described previously (Yang et al., 2013). In brief, DNA was labeled with the fluorescent dye Cy-5 using a random priming method and then purified with the QIA quick purification kit (Qiagen, Valencia, CA, USA) according to the manufacturer's instructions. After checking the dye incorporation on a NanoDrop ND-1000 spectrophotometer (NanoDrop Technologies, Wilmington, DE, USA), DNA was dried in a SpeedVac (ThermoSavant, Milford, MA, USA) at $45^{\circ} \mathrm{C}$ for $45 \mathrm{~min}$. Subsequently, labeled DNA was resuspended in $120 \mu l$ hybridization solution containing $40 \%$ formamide, $3 \times$ SSC, $10 \mu \mathrm{g}$ of unlabeled herring sperm DNA (Promega, Madison, WI, USA), and $0.1 \%$ SDS. The hybridizations were performed with a MAUI hybridization station (BioMicro, Salt Lake City, UT, USA) according to the manufacturer's instructions. After washing and drying, microarray was scanned by a NimbleGen MS200 scanner (Roche, Madison, WI, USA) at $633 \mathrm{~nm}$ using a laser power of $100 \%$ and a photomultiplier tube (PMT) gain of $75 \%$. Signal intensities were subsequently quantified. Briefly, raw data were processed as following: (i) poor-quality spots, those flagged or with a signal to noise ratio (SNR) $<2.0$, were removed; (ii) at least two valid values of three biological replicates were required for each probe; (iii) relative abundance normalization was applied to all data; and (iv) natural logarithmic transformation was used before statistical analyses.

\section{Statistical analyses}

We used a pure random-effects model to estimate the overall weighted mean effect size of cooling on environmental variables and functional genes, based on the method of meta-analysis of response ratios (Hedges et al., 1999). Briefly, for each of the six comparison pairs (3200T3400 vs 3200, 3200T3600 vs $3200,3200 \mathrm{~T} 3800$ vs $3200,3400 \mathrm{~T} 3600$ vs 3400 , 3400 T3800 vs 3400 and 3600 T3800 vs 3600), the effect size, represented by the response ratio (RR) metric, was calculated as log-proportional change between the means of the transplant and control group. To correct potential bias introduced by small sample sizes, we used the bias-corrected metric $\mathrm{RR}^{\Delta}$ and validated the accuracy of $R^{\Delta}$ metric with Geary's test for each comparison pair prior to pooling outcomes (Lajeunesse, 2015). For each pair of transplant-control comparison, the effect size $R^{\Delta}$ was calculated as:

$$
\begin{aligned}
R R^{\Delta} & =R R+\frac{1}{2}\left[\frac{(s \cdot d \cdot \mathrm{T})^{2}}{N_{T} \bar{X}_{T}^{2}}-\frac{(s \cdot d \cdot \mathrm{C})^{2}}{N_{C} \bar{X}_{C}^{2}}\right] \\
& =\ln \frac{\bar{X}_{T}}{\bar{X}_{C}}+\frac{1}{2}\left[\frac{(s \cdot d \cdot \mathrm{T})^{2}}{N_{T} \bar{X}_{T}^{2}}-\frac{(s \cdot d \cdot \mathrm{C})^{2}}{N_{C} \bar{X}_{C}^{2}}\right]
\end{aligned}
$$

where $\bar{X}_{\mathrm{T}}$ and $\bar{X}_{\mathrm{C}}$ represent the mean of the variable in transplant and control group; s.d. ${ }_{\mathrm{T}}$ and s.d.C $_{\mathrm{C}_{\mathrm{C}}}$ 
represent standard deviations of transplant and control group; $N_{\mathrm{T}}$ and $N_{\mathrm{C}}$ represent the number of replicates of transplant and control group.

The sample sizes and standard deviations were used to help quantify the sampling variability in the effect size $\mathrm{RR}^{\Delta}$ within each comparison. For each comparison, the variance of $\mathrm{RR}^{\Delta}$ (denoted by $v$ ) was calculated as:

$v=\frac{(\text { s.d.T })^{2}}{N_{\mathrm{T}} \bar{X}_{\mathrm{T}}^{2}}+\frac{(\text { s.d.C })^{2}}{N_{\mathrm{C}} \bar{X}_{\mathrm{C}}^{2}}+\frac{1}{2}\left[\frac{(\text { s.d.T })^{4}}{N_{\mathrm{T}}^{2} \bar{X}_{\mathrm{T}}^{4}}+\frac{(\text { s.d.C })^{4}}{N_{\mathrm{C}}^{2} \bar{X}_{\mathrm{C}}^{4}}\right]$

The random between-comparisons variance component was calculated as:

$\hat{\sigma}_{\lambda}^{2}=\frac{Q-(k-1)}{\sum_{i=1}^{k} w_{i}-\frac{\sum_{i=1}^{k} w_{i}^{2}}{\sum_{i=1}^{k} w_{i}}}$

Where

$Q=\sum_{i=1}^{k} w_{i}\left(\mathrm{RR}_{i}^{\Lambda}\right)^{2}-\frac{\left(\sum_{i=1}^{k} w_{i} \mathrm{RR}_{i}^{\Lambda}\right)^{2}}{\sum_{i=1}^{k} w_{i}}$

and $w_{i}=1 / v_{i}, k$ is the number of comparisons. In this study, $k=6$.

The within-comparison variance and the betweencomparisons variance component were converted into weights to help minimize the influence of comparisons with low statistical power when analyzing and pooling multiple study outcomes. The weight of each comparison was determined as:

$w_{i}^{*}=\frac{1}{v_{i}+\hat{\sigma}_{\lambda}^{2}}$

The weighted mean effect size $\left(\overline{\mathrm{RR}^{*}}\right)$ and its standard error were then determined based on the effect size and the weight of each comparison:

$$
\begin{aligned}
& \overline{\mathrm{RR}^{*}}=\frac{\sum_{i=1}^{k} w_{i}^{*} \mathrm{RR}_{i}^{4}}{\sum_{i=1}^{k} w_{i}^{*}} \\
& \text { s.e. }\left(\overline{\mathrm{RR}^{*}}\right)=\sqrt{\frac{1}{\sum_{i=1}^{k} w_{i}^{*}}}
\end{aligned}
$$

In addition, we examined the Pearson correlation between the effect size and the cooling degree, that is, the air temperature difference. For variables whose effect sizes were positively and significantly $(P<0.05)$ correlated with the cooling degree, the average change per ${ }^{\circ} \mathrm{C}$ cooling was calculated as the mean of the absolute change divided by the cooling degree in each comparison.

To test the cooling effects on the microbial community structure, three different complementary non-parametric dissimilarity analyses for multivariate data were used: analysis of similarity (ANOSIM) (Clarke, 1993), non-parametric multivariate analysis of variance (adonis) (Anderson, 2001) using distance matrices, and multi-response permutation procedure (MRPP) (McCune et al., 2002). The Detrended Correspondence Analysis (DCA) (Hill and H.G.
Gauch, 1980) was used to visualize the difference of microbial community structure between cooling sample and its corresponding control.

The Canonical Correspondence Analysis (CCA) was performed to determine the most significant environmental variables linking to microbial functional gene structure (Ramette and Tiedje, 2007). Based on the variance inflation factors (VIF) values, redundant variables with $\mathrm{VIF}>20$ were removed from the CCA model. A partial-CCA based Variation Partitioning Analysis (VPA) was then performed to determine the contribution of different groups of variables. To determine the effects of microbial functional gene or environmental variables on greenhouse gas flux, partial Mantel tests (Smouse et al., 1986) were performed in which the co-varying effects between microbial functional gene structure and environmental variables were controlled. BrayCurtis coefficient and Euclidean distance were used to construct dissimilarity matrices of microbial communities and environmental variables, respectively.

\section{Results and Discussion}

For the six comparison pairs; $3200 \mathrm{~T} 3400$ vs 3200 , $3200 \mathrm{~T} 3600$ vs $3200,3200 \mathrm{~T} 3800$ vs $3200,3400 \mathrm{~T} 3600$ vs $3400,3400 \mathrm{~T} 3800$ vs 3400 and $3600 \mathrm{~T} 3800$ vs 3600 , air temperature decreased by $0.26,1.00,2.09,0.74$, 1.83 and $1.09{ }^{\circ} \mathrm{C}$, respectively (Supplementary Table 1). We calculated the weighted mean effect sizes of cooling on environmental variables. The temperature of the top $5 \mathrm{~cm}$ and lower $20 \mathrm{~cm}$ of the soil profile significantly decreased, with mean effect size of $-0.22( \pm 0.05$ s.e. $)$ and $-0.23( \pm 0.05)$. The effect size of soil temperature of the top $5 \mathrm{~cm}$ profile was significantly correlated with the cooling degree (Pearson's $r=0.82, P=0.04$ ) across the six comparisons. Further analysis showed that soil temperature of the top $5 \mathrm{~cm}$ profile decreased by $2.41( \pm 0.48){ }^{\circ} \mathrm{C}$ per ${ }^{\circ} \mathrm{C}$ decrease in air temperature. Soil $\mathrm{pH}$ marginally significantly decreased under cooling, with an effect size of $-0.02( \pm 0.01)$, while soil moisture remained largely unchanged. In addition, plant species richness remained unchanged, but the plant biomass and total plant coverage (TCOV) responses were negative, with effect sizes of $-0.53( \pm 0.17)$ and -0.07 ( \pm 0.04 ), respectively (Figure 1 ). These results were consistent with known cooling effects (Campbell and McAndrews, 1993), demonstrating that the field simulation we performed was reliable. Also, they directly contrasted observations from warming-based studies, in which plant productivity increased in tundras, grasslands and forests (Lal, 2005; Zhou et al., 2012; Natali et al., 2014).

Amplicon sequencing of the 16S rRNA gene was combined with GeoChip 4.0 (Tu et al., 2014) to examine soil microbial communities. GeoChip 4.0 is a microarray containing probes to detect $\sim 141995$ gene sequences from 410 gene families derived from 


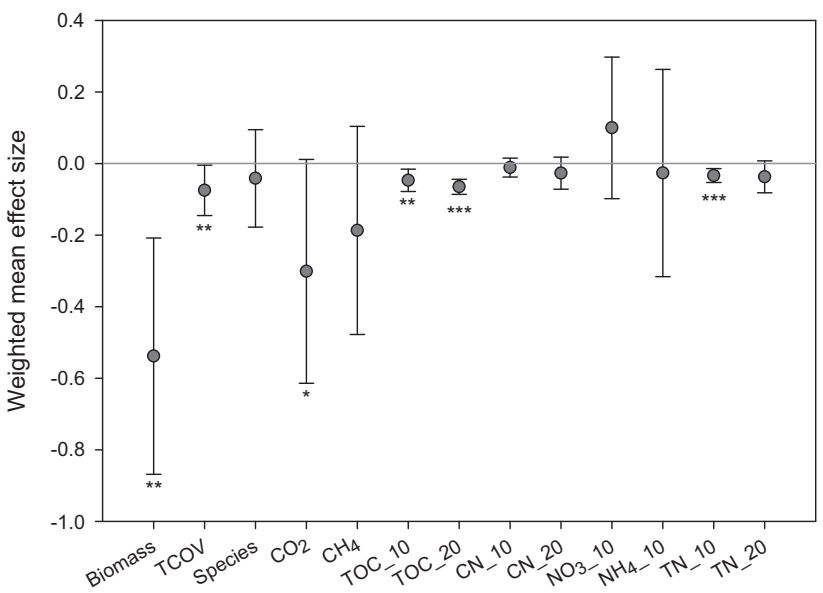

Figure 1 Effects of climate cooling on various environmental variables. The weighted mean effect size was calculated by the method of meta-analysis of response ratio. Error bars are at the $95 \%$ confidence level. The significance level is indicated by asterisk: ${ }^{* *} P<0.001,{ }^{*} P<0.050$, and ${ }^{*} P<0.100$. For the environmental variables, Biomass-plant biomass; TCOV-total plant coverage; Species-plant species richness; TOC 10 and TOC 20-total soil organic $C$ at the $0-10 \mathrm{~cm}$ depth and $10-20 \mathrm{~cm}$ depth; TN 10 and TN 20-total soil $\mathrm{N}$ at the $0-10 \mathrm{~cm}$ depth and 10-20 cm depth; CN_10 and CN_20-the ratio of TOC to TN ratio at the $0-10 \mathrm{~cm}$ depth and $10-20 \mathrm{~cm}$ depth; $\mathrm{NO}_{3-} 10$ - soil nitrate at the $0-10 \mathrm{~cm}$ depth; and $\mathrm{NH}_{3-} 10$ - soil ammonia at the 0-10 cm depth.

bacteria, archaea or fungi, including genes associated with nitrogen (N), carbon (C), sulfur (S) and phosphorus (P) cycling, metal resistance, organic remediation, and other processes. DCA and dissimilarity tests showed that, for each transplant-control comparison, both taxonomic composition and functional gene structure of microbial communities in transplanted soils differed compared with in-place controls (Table 1; Supplementary Figure 1; $P<0.05$ ). In addition, the Mantel test showed a very weak but significant correlation $(r=0.18, P=0.03)$ between the variations of $16 \mathrm{~S}$ rRNA gene data and GeoChip data across samples, unveiling some consistency between microbial taxonomic composition and functional gene structure. Furthermore, CCA indicated that microbial functional gene structure correlated $(P<0.01)$ with changes in soil temperature, $\mathrm{pH}$, moisture, $\mathrm{NH}_{3}-\mathrm{N}$, TOC, TN, C/N ratio, plant biomass, plant species richness and TCOV (Supplementary Figure 2). A total of $63.6 \%$ of the variation in soil microbial functional gene structure could be explained by soil climatic variables $(13.1 \%)$, soil geochemical variables $(26.9 \%)$, plant variables $(8.8 \%)$ and their interactions (Supplementary Figure 2), as indicated by VPA. It is noted that microbial functional gene structure of 3200T3400 was more similar to that of $3200 \mathrm{~T} 3800$ rather than 3200 T3600 (Supplementary Figure 1). A possible explanation is that some environmental variables were more similar between $3400 \mathrm{~m}$ and $3800 \mathrm{~m}$ sites than with the $3600 \mathrm{~m}$ site, such as plant biomass and $\mathrm{pH}$, which may have important roles in shaping microbial functional gene structure. In fact, the
Table 1 Effects of cooling on microbial community compositions and functional genes with three different statistical approaches

\begin{tabular}{|c|c|c|c|c|c|c|}
\hline \multirow[t]{2}{*}{ Data sets } & \multicolumn{2}{|c|}{ adonis } & \multicolumn{2}{|c|}{ ANOSIM } & \multicolumn{2}{|c|}{$M R P P$} \\
\hline & $F$ & $\mathrm{P}$-value & $R$ & $\mathrm{P}$-value & $\delta$ & $\mathrm{P}$-value \\
\hline 16S sequencing & 1.763 & 0.005 & 0.363 & 0.008 & 0.695 & 0.009 \\
\hline $\begin{array}{l}\text { All GeoChip } \\
\text { genes }\end{array}$ & 3.521 & 0.018 & 0.160 & 0.020 & 0.232 & 0.014 \\
\hline C cycling genes & 3.537 & 0.015 & 0.166 & 0.024 & 0.239 & 0.012 \\
\hline $\mathrm{N}$ cycling genes & 3.557 & 0.019 & 0.174 & 0.012 & 0.233 & 0.010 \\
\hline
\end{tabular}

changes of most environmental variables and microbial functional structure were not related to the degree of cooling.

Carbon decomposition and nutrient cycling were both impacted by cooling. Both the relative abundance and $\alpha$-diversity (Simpson index) of genes associated with chemically labile $\mathrm{C}$ decomposition were markedly decreased in the transplanted plots, as indicated by the weighted mean effect sizes. These included $a p u, c d a$ and glucoamylase genes for starch decomposition, xylA and mannanase genes for hemi-cellulose decomposition, exochitinase genes for chitin decomposition, and pectinase genes for pectin decomposition (Figure 2; Supplementary Figure 3), which have previously been shown to increase in response to warming (Zhou et al., 2012). The most notably decreased $\mathrm{C}$ decomposition genes included cda genes derived from Vibrio harveyi HY01 and Roseburia intestinalis L1-82, mannanase genes derived from Cellvibrio japonicus Ueda107 and Streptomyces sviceus ATCC 29083 (Supplementary Figure 4). Consistently, the 16S rRNA gene amplicon data showed significant decreases in the relative abundances of the Streptomyces genus. In fact, the relative abundance of Gammaproteobacteria, Firmicutes and Actinobacteria were significantly decreased under cooling (Supplementary Figure 5). Interestingly, the functional genes responsible for the decomposition of chemically recalcitrant $\mathrm{C}$, such as lignin and aromatics, which account for about $95 \%$ of topsoil organic C in Tibetan grasslands (Genxu et al., 2002), were unchanged. Chemically recalcitrant $\mathrm{C}$ was previously thought to be stable in soil and used by microorganisms only when labile $\mathrm{C}$ substrates are exhausted (Lützow et al., 2006). However, there is accumulating evidence that microorganisms decompose chemically recalcitrant $\mathrm{C}$ under suitable conditions, and that not all old and stable C compounds are as persistent as once considered (Kleber et al., 2011; Lehmann and Kleber, 2015). Soil heterotrophic respiration was consistently steady at our study site (Hu et al., 2008), which would be expected under consistent rates of $\mathrm{C}$ decomposition.

The abundance of most nutrient cycling genes either decreased or remained unchanged except ureC. For $\mathrm{N}$ cycling genes, the abundances of amoA genes decreased (Supplementary Figure 6a), which 


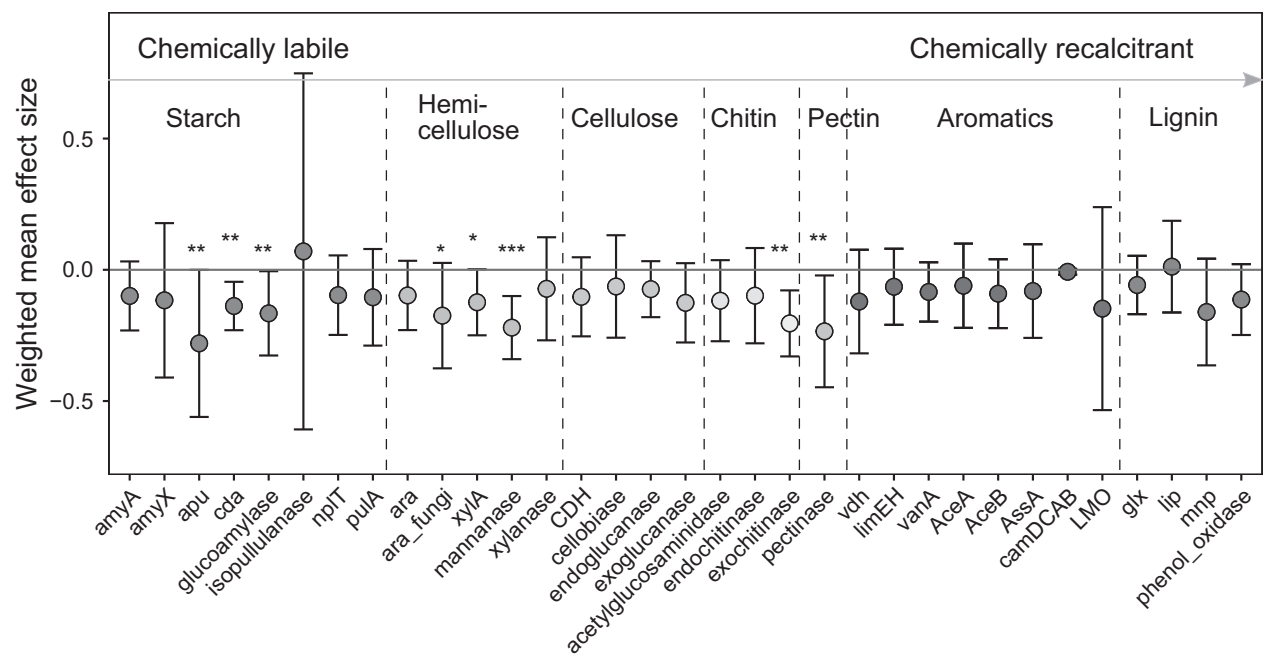

Figure 2 Effects of climate cooling on relative abundances of $\mathrm{C}$ decomposition genes. The weighted mean effect size was calculated by the method of meta-analysis of response ratio. Error bars are at the $95 \%$ confidence level. The significance level is indicated by asterisk: ${ }^{* * *} P<0.001,{ }^{* *} P<0.050$ and ${ }^{*} P<0.100$.

Table 2 The influence of environmental variables and microbial functional genes on greenhouse gas emission by partial Mantel test

\begin{tabular}{|c|c|c|c|c|c|c|}
\hline \multirow{2}{*}{$\frac{\text { Effects of }}{\text { Controlling for }}$} & \multicolumn{2}{|c|}{ Functional gene groups ${ }^{a}$} & \multicolumn{2}{|c|}{ Soil variables } & \multicolumn{2}{|c|}{ Plant variables } \\
\hline & Soil variables ${ }^{\mathrm{b}}$ & Plant variables ${ }^{\mathrm{C}}$ & Functional gene & Plant variables & Functional gene & Soil variables \\
\hline $\mathrm{CO}_{2}$ flux & $-0.310^{\mathrm{d}}$ & 0.045 & $0.615^{* * *}$ & $0.458^{* * *}$ & $0.406 * * *$ & $0.198 * *$ \\
\hline $\mathrm{CH}_{4}$ flux & $0.159^{*}$ & $0.143^{*}$ & -0.002 & -0.031 & $0.213^{*}$ & $0.226^{*}$ \\
\hline $\mathrm{N}_{2} \mathrm{O}$ flux & 0.331 ** & $0.345^{* *}$ & -0.039 & 0.116 & 0.039 & 0.050 \\
\hline
\end{tabular}

${ }^{\mathrm{a}}$ Functional gene groups were carbon decomposition genes for $\mathrm{CO}_{2}$ flux, $m m o X$ genes for $\mathrm{CH}_{4}$ flux and norB genes for $\mathrm{N}_{2} \mathrm{O}$ flux. ${ }^{\text {bSoil }}$ variables included for testing the relationship with $\mathrm{CO}_{2}$ or $\mathrm{CH}_{4}$ flux: soil temperature, soil moisture, $\mathrm{pH}, \mathrm{TOC}, \mathrm{C} / \mathrm{N}$ ratio. Soil variables included for testing the relationship with $\mathrm{N}_{2} \mathrm{O}$ flux: soil temperature, soil moisture, $\mathrm{pH}, \mathrm{NO}_{3}-\mathrm{N}, \mathrm{NH}_{3}-\mathrm{N}$, TN, C/N ratio. 'Plant variables were plant biomass, total coverage of plants (TCOV) and plant species richness. ${ }^{\mathrm{d}}$ The $r$-value of Partial Mantel test is shown. Significance: ${ }^{* * *} P<0.001,{ }^{* *} P<0.050$, ${ }^{*} P<0.100$.

were derived from both ammonia-oxidizing archea (AOA) and ammonia-oxidizing bacteria (AOB) (Wessén et al., 2011). The most notably decreased amoA genes included those derived from uncultured archaea, Edwardsiella tarda EIB202 and Pseudomonas putida KT2440 (Supplementary Figure 6b), which was consistent with the amplicon sequencing data showing that the relative abundance of Gammaproteobacteria significantly decreased under cooling (Supplementary Figure 5). The abundance of nor $B$ genes encoding an enzyme to convert NO to $\mathrm{N}_{2} \mathrm{O}$ in both nitrification and denitrification processes decreased, too (Supplementary Figure 6a, $P<0.05$ ). However, we could not determine which process the nor $B$ genes belong to.

The ecosystem respiration (Re, represented by the measured $\mathrm{CO}_{2}$ flux) response was negative, with an effect size of $-0.30( \pm 0.15)$ (Figure 1), similar to a recent cooling experiment in forests (Luan et al., 2014). However, partial Mantel tests demonstrated an insignificant correlation between $\mathrm{C}$ decomposition gene abundance and $\mathrm{CO}_{2}$ flux when soil or plant variables were controlled (Table 2). Rather, soil and plant variables showed a correlation $(P<0.001)$ with $\mathrm{CO}_{2}$ flux when controlled for $\mathrm{C}$ decomposition genes.
Specifically, plant biomass, TCOV, plant species richness, soil temperature, $\mathrm{pH}$ and TOC at a depth of $0-10 \mathrm{~cm}$ positively correlated with $\mathrm{CO}_{2}$ flux, whereas soil moisture negatively correlated (Figure 3a; Supplementary Figure 7). The forward stepwise regression method was applied to select variables for predicting $\mathrm{CO}_{2}$ flux based on Akaike information criterion (AIC). The final linear model included two variables of air temperature and TCOV, which was able to explain $\sim 90 \%(P<0.001)$ of the variation in $\mathrm{CO}_{2}$ flux (Supplementary Table 2). Furthermore, partial correlation analysis showed that air temperature positively and significantly correlated with $\mathrm{CO}_{2}$ flux $(r=0.75, P=0.05)$ when soil and plant variables were controlled. The decrease in air temperature (that is, cooling) could be the major driver of $\mathrm{Re}$ decrease, since often biological activities are controlled by temperature (Brown et al., 2004). The positive correlation $\left(r^{2}=0.57, \quad P<0.001\right)$ between plant biomass and $\mathrm{CO}_{2}$ flux (Figure 3a) together with the partial Mantel test results (Table 2) suggested that a reduction in ecosystem respiration might be primarily attributed to decreased autotrophic respiration under cooling. Consistently, plant autotrophic respiration was 

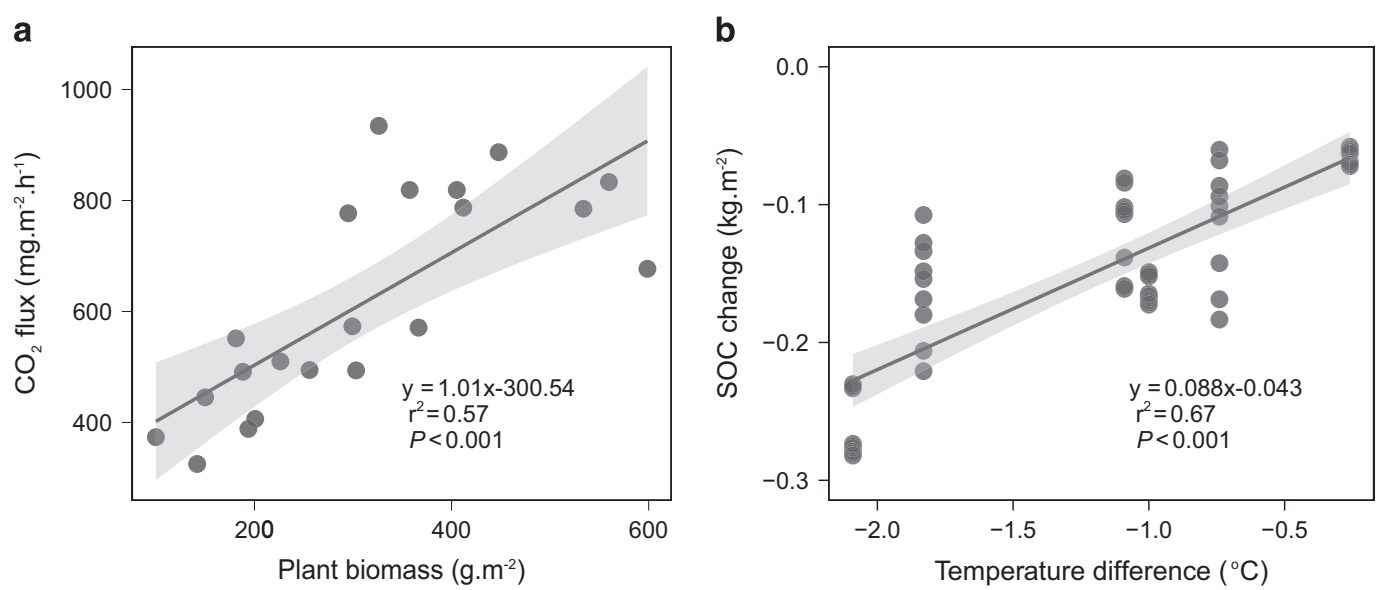

Figure 3 (a) Correlation between $\mathrm{CO}_{2}$ efflux and plant biomass and (b) correlation between the change of SOC density and temperature difference. Linear regression lines and their 95\% confidence limits (shaded) are shown. SOC Change was calculated as the difference in SOC density between transplant soils (cooling) and their corresponding controls. Negative values of SOC changes indicate the decrease of SOC under cooling.

shown to be the main explanatory factor of variations in ecosystem respiration on the Tibetan alpine grasslands (Hu et al., 2008). Further, soil TOC at depths of $0-10$ and $10-20 \mathrm{~cm}$ were decreased, with effect sizes of $-0.05( \pm 0.02)$ and $-0.06( \pm 0.01)$, respectively (Figure 1). The effect size of soil TOC at depths of $10-20 \mathrm{~cm}$ strongly and significantly correlated with the cooling degree (Pearson's $r=0.91$, $P=0.01$ ), and soil TOC at depths of $10-20 \mathrm{~cm}$ decreased by $2.55( \pm 0.44) \mathrm{mg} \mathrm{g}^{-1}$ per ${ }^{\circ} \mathrm{C}$ decrease in air temperature.

TN contents at the depths of $0-10 \mathrm{~cm}$ decreased, with an effect size of $-0.03( \pm 0.01)$, though the $\mathrm{C} / \mathrm{N}$ ratio remained largely unchanged (Figure 1). The $\mathrm{N}_{2} \mathrm{O}$ fluxes were either decreased ( $t$-test, $P<0.05$ ) or unchanged by cooling (Supplementary Table 1), which was consistent with previous studies showing that the effect of temperature on $\mathrm{N}_{2} \mathrm{O}$ emission is generally positive in non-wetland soils (Smith, 1997). $\mathrm{N}_{2} \mathrm{O}$ flux was significantly correlated $(P<0.006)$ with the abundance of nor $B$ genes when soil or plant variables were controlled (Table 2), suggesting that $\mathrm{N}_{2} \mathrm{O}$ flux in these sites was microbially-driven (Singh et al., 2010). The grassland appeared to be a $\mathrm{CH}_{4}$ sink rather than a source (Supplementary Table 1), implying that $\mathrm{CH}_{4}$ oxidation could have a more important role in $\mathrm{CH}_{4}$ flux than $\mathrm{CH}_{4}$ production. In support of this, mcrA abundance, associated with $\mathrm{CH}_{4}$ production, was not correlated to $\mathrm{CH}_{4}$ flux. In contrast, the abundance of $m m o X$, associated with $\mathrm{CH}_{4}$ oxidation, including those derived from methanotrophs possessing the soluble methane monooxygenase such as Methylocella spp. and Methylomonas spp., was correlated with $\mathrm{CH}_{4}$ flux $(P<0.100)$ (Table 2). Methane flux remained unchanged under cooling (Supplementary Table 1; Figure 1). In comparison, previous studies showed that soil $\mathrm{CH}_{4}$ uptake increased (Peterjohn et al., 1994; Hart, 2006) or remained unchanged (Torn and Harte, 1996; Rustad and Fernandez, 1998) under warming. As $\mathrm{CH}_{4}$ production is an anaerobic process, soil moisture might have stronger influence on soil $\mathrm{CH}_{4}$ fluxes than soil temperature (Bowden et al., 1998; Wei et al., 2015).

To determine whether the lower soil $\mathrm{C}$ was related to cooling, we calculated the correlation between the decrease of SOC density ( $\mathrm{kg} \mathrm{C} \mathrm{m}^{-2}$ ) under cooling and the temperature difference. SOC loss in the top $20 \mathrm{~cm}$ was correlated $\left(r^{2}=0.67, P<0.001\right)$ with the degree of cooling (Figure 3b). Although there were considerable variations in the SOC changes at certain temperature differences, all of the SOC changes are exclusively negative. The SOC decrease for the extreme of the altitudinal transplant experiment (from 3200 to $3800 \mathrm{~m}$ ) was the largest. When the data of this pair was removed, the linear and significant correlation between SOC change and temperature difference still holds $\left(r^{2}=0.44\right.$, $P<0.001)$. The decrease of SOC was estimated to be $0.088 \mathrm{~kg} \mathrm{C} \mathrm{m} \mathrm{m}^{-2} \mathrm{C}^{-1}$, ranging from 0.071 to $0.105 \mathrm{~kg} \mathrm{C} \mathrm{m}^{-2}{ }^{\circ} \mathrm{C}^{-1}$ at the $95 \%$ confidence level. By extrapolating these observations to the entire Tibetan plateau, it is estimated that a $1^{\circ} \mathrm{C}$ decrease in temperature would result in a roughly $0.1 \mathrm{Pg}$ SOC loss plateau-wide, which accounts for about $0.3 \%$ of the SOC stored in the Tibetan plateau (Genxu et al., 2002). However, obviously, this extrapolation should be considered a rough estimation due to the heterogeneity of the plateau, which will likely result in substantial variance in responses of the soil microbial community.

Various studies have suggested that climate warming would result in soil C loss through increased soil respiration (Frey et al., 2013). Therefore, warming will feedback positively on climate change. However, recent studies showed contradictory results. For example, long-term warming has increased net ecosystem C storage on Arctic tundra, while the soil carbon storage remained unchanged (Sistla et al., 2013). In a downward 
transplant warming experiment, we also found that SOC remained unchanged under warming (Yue et al., 2015). In the current study, however, we found that SOC was significantly decreased under cooling (Figure 3b; Supplementary Table 1). A possible explanation is that the decrease in soil $\mathrm{C}$ inputs through litter and root exudates was not offset by the decrease in soil $\mathrm{C}$ consumption through respiration. Plant biomass decreased under cooling, suggesting a significant decrease in soil C inputs. In contrast, the abundance and presence of chemically recalcitrant $\mathrm{C}$ decomposition genes were largely unchanged. Persistent microbiallydriven turnover of chemically recalcitrant carbon accelerates soil $\mathrm{C}$ loss, since the chemically recalcitrant C constitutes the majority of topsoil C in Tibetan grasslands (Genxu et al., 2002). Even though soil C loss by climate cooling was similar to that observed under warming (Cox et al., 2000; Nie et al., 2013), we propose that the underlying mechanisms are fundamentally different.

Our results highlight the importance of understanding the role of plant and microbial communities in providing ecosystem feedbacks to climate change. To improve the prediction of ecosystem feedbacks to climate cooling, it is important to consider various types of feedback mechanisms resulting from the changes in plant and microbial community ecology. Our findings also provide insights into ecological consequences of numerous cooling events in earth's history.

\section{Data accessibility}

GeoChip data are available online (www.ncbi.nlm. nih.gov/geo/) with the accession number GSE52425. 454 sequencing data are available from the MGRAST database (accession no. 4565936.3 to 4565973.3).

\section{Conflict of Interest}

The authors declare no conflict of interest.

\section{Acknowledgements}

We thank Haibei Research Station staff for sampling, Hao $\mathrm{Yu}$ for GeoChip assistance. This research was supported by grants to Yunfeng Yang from the National Key Basic Research Program of China (2013CB956601), the Strategic Priority Research Program of the Chinese Academy of Sciences (XDB15010102), and National Science Foundation of China (41471202), to Shiping Wang from the National Basic Research Program (2013CB956000) and National Science Foundation of China (41230750), and to Jizhong Zhou from the National Science Foundation of China (41430856), and the United States Department of Energy, Biological Systems Research on the Role of Microbial Communities in Carbon Cycling Program (DESC0010715).

\section{Author contributions}

This study was conceived and led by SW, JZ and YY; YH, QL, XL and YY carried out GeoChip experiments and environmental measurements; LW and HY performed the analytical work; LW, YY and JZ wrote the manuscript with the help from SW, ZH, JVN, LH and JG.

\section{References}

Alley RB, Marotzke J, Nordhaus W, Overpeck J, Peteet D, Pielke R et al. (2003). Abrupt climate change. Science 299: 2005-2010.

Anderson MJ. (2001). A new method for non-parametric multivariate analysis of variance. Austral Ecol 26: 32-46.

Bowden RD, Newkirk KM, Rullo GM. (1998). Carbon dioxide and methane fluxes by a forest soil under laboratory-controlled moisture and temperature conditions. Soil Biol Biochem 30: 1591-1597.

Breeuwer A, Heijmans MM, Robroek BJ, Berendse F. (2010). Field simulation of global change: transplanting northern bog mesocosms southward. Ecosystems 13: $712-726$.

Brown JH, Gillooly JF, Allen AP, Savage VM, West GB. (2004). Toward a metabolic theory of ecology. Ecology 85: 1771-1789.

Campbell ID, McAndrews JH. (1993). Forest disequilibrium caused by rapid Little Ice Age cooling. Nature 366: $336-338$.

Clarke KR. (1993). Non-parametric multivariate analyses of changes in community structure. Austr J Ecol 18: 117-117.

Cox PM, Betts RA, Jones CD, Spall SA, Totterdell IJ. (2000). Acceleration of global warming due to carbon-cycle feedbacks in a coupled climate model. Nature 408: 184-187.

Doran PT, Priscu JC, Lyons WB, Walsh JE, Fountain AG, McKnight DM et al. (2002). Antarctic climate cooling and terrestrial ecosystem response. Nature 415: 517-520.

Easterling DR, Wehner MF. (2009). Is the climate warming or cooling. Geophys Res Lett 36: 8.

Frey SD, Lee J, Melillo JM, Six J. (2013). The temperature response of soil microbial efficiency and its feedback to climate. Nat Clim Change 3: 395-398.

Genxu W, Ju Q, Guodong C, Yuanmin L. (2002). Soil organic carbon pool of grassland soils on the QinghaiTibetan Plateau and its global implication. Sci Total Environ 291: 207-217.

Hart SC. (2006). Potential impacts of climate change on nitrogen transformations and greenhouse gas fluxes in forests: a soil transfer study. Global Change Biol 12: 1032-1046.

Hedges LV, Gurevitch J, Curtis PS. (1999). The metaanalysis of response ratios in experimental ecology. Ecology 80: 1150-1156.

Hill MO, H.G. Gauch J. (1980). Detrended correspondence analysis: an improved ordination technique. Vegetatio 42: 47-58.

Hu QW, Wu Q, Cao GM, Li D, Long RJ, Wang YS. (2008). Growing season ecosystem respirations and associated 
component fluxes in two alpine meadows on the Tibetan Plateau. J Integr Plant Biol 50: 271-279.

Ji F, Wu Z, Huang J, Chassignet EP. (2014). Evolution of land surface air temperature trend. Nat Clim Change 4: 462-466.

Kleber M, Nico PS, Plante A, Filley T, Kramer M, Swanston C et al. (2011). Old and stable soil organic matter is not necessarily chemically recalcitrant: implications for modeling concepts and temperature sensitivity. Global Change Biol 17: 1097-1107.

Klein JA, Harte J, Zhao X-Q. (2007). Experimental warming, not grazing, decreases rangeland quality on the Tibetan Plateau. Ecol Appl 17: 541-557.

Lajeunesse MJ. (2015). Bias and correction for the log response ratio in ecological meta-analysis. Ecology $\mathbf{9 6}$ 2056-2063.

Lal R. (2005). Forest soils and carbon sequestration. Forest Ecol Manage 220: 242-258.

Lehmann J, Kleber M. (2015). The contentious nature of soil organic matter. Nature 528: 60-68.

Lin X, Zhang Z, Wang S, Hu Y, Xu G, Luo C et al. (2011). Response of ecosystem respiration to warming and grazing during the growing seasons in the alpine meadow on the Tibetan plateau. Agric Forest Meteorol 151: 792-802.

Luan J, Liu S, Chang SX, Wang J, Zhu X, Liu K et al. (2014). Different effects of warming and cooling on the decomposition of soil organic matter in warm-temperate oak forests: a reciprocal translocation experiment. Biogeochemistry 121: 551-564.

Lucht W, Prentice IC, Myneni RB, Sitch S, Friedlingstein P, Cramer W et al. (2002). Climatic control of the highlatitude vegetation greening trend and Pinatubo effect. Science 296: 1687-1689.

Luo Y. (2007). Terrestrial carbon-cycle feedback to climate warming. Annu Rev Ecol Evol Syst 38: 683-712.

Lützow Mv, Kögel-Knabner I, Ekschmitt K, Matzner E, Guggenberger G, Marschner B et al. (2006). Stabilization of organic matter in temperate soils: mechanisms and their relevance under different soil conditionsa review. Eur J Soil Sci 57: 426-445.

Lyubushin AA, Klyashtorin LB. (2012). Short term global dT prediction using (60-70)-years periodicity. Energy Environ 23: 75-86.

Ma X, Wang S, Wang Y, Jiang G, Nyren P. (2006). Shortterm effects of sheep excrement on carbon dioxide, nitrous oxide and methane fluxes in typical grassland of Inner Mongolia. N Zeal J Agric Res 49: 285-297.

McAnena A, Flögel S, Hofmann P, Herrle J, Griesand A, Pross J et al. (2013). Atlantic cooling associated with a marine biotic crisis during the mid-Cretaceous period. Nat Geosci 6: 558-561.

McCune B, Grace JB, Urban DL. (2002), Analysis of ecological communities, vol. 28. MjM software design Gleneden Beach, OR.

Natali SM, Schuur EAG, Webb EE, Pries CEH, Crummer KG. (2014). Permafrost degradation stimulates carbon loss from experimentally warmed tundra. Ecology 95: 602-608.

Nie M, Pendall E, Bell C, Gasch CK, Raut S, Tamang S et al. (2013). Positive climate feedbacks of soil microbial communities in a semi-arid grassland. Ecol Lett 16: 234-241.

Petchey OL, McPhearson PT, Casey TM, Morin PJ. (1999). Environmental warming alters food-web structure and ecosystem function. Nature 402: 69-72.
Peterjohn WT, Melillo JM, Steudler PA, Newkirk KM, Bowles FP, Aber JD. (1994). Responses of trace gas fluxes and $\mathrm{N}$ availability to experimentally elevated soil temperatures. Ecol Appl 4: 617-625.

Qiu J. (2008). China: the third pole. Nat News 454: 393-396.

Ramette A, Tiedje JM. (2007). Multiscale responses of microbial life to spatial distance and environmental heterogeneity in a patchy ecosystem. Proc Natl Acad Sci USA 104: 2761-2766.

Rui J, Li J, Wang S, An J, Liu W-t, Lin Q et al. (2015). Responses of bacterial communities to simulated climate changes in alpine meadow soil of the Qinghai-Tibet Plateau. Appl Environ Microbiol 81: 6070-6077.

Rustad LE, Fernandez IJ. (1998). Experimental soil warming effects on $\mathrm{CO} 2$ and $\mathrm{CH} 4$ flux from a low elevation spruce-fir forest soil in Maine, USA. Global Change Biol 4: 597-605.

Ryba SA, Burgess RM. (2002). Effects of sample preparation on the measurement of organic carbon, hydrogen, nitrogen, sulfur, and oxygen concentrations in marine sediments. Chemosphere 48: 139-147.

Singh BK, Bardgett RD, Smith P, Reay DS. (2010). Microorganisms and climate change: terrestrial feedbacks and mitigation options. Nat Rev Microbiol 8: 779-790.

Sistla SA, Moore JC, Simpson RT, Gough L, Shaver GR, Schimel JP. (2013). Long-term warming restructures Arctic tundra without changing net soil carbon storage. Nature 497: 615-618.

Smith K. (1997). The potential for feedback effects induced by global warming on emissions of nitrous oxide by soils. Global Change Biol 3: 327-338.

Smouse PE, Long JC, Sokal RR. (1986). Multiple regression and correlation extensions of the Mantel test of matrix correspondence. Syst Zool 35: 627-632.

Song C, Yan B, Wang Y, Wang Y, Lou Y, Zhao Z. (2003). Fluxes of carbon dioxide and methane from swamp and impact factors in Sanjiang Plain, China. Chin Sci Bull 48: 2749-2753.

Torn MS, Harte J. (1996). Methane consumption by montane soils: implications for positive and negative feedback with climatic change. Biogeochemistry 32: 53-67.

Tu Q, Yu H, He Z, Deng Y, Wu L, Nostrand JD et al. (2014). GeoChip 4: a functional gene-array-based highthroughput environmental technology for microbial community analysis. Mol Ecol Resour 14: 914-928.

Turner J, Lu H, White I, King JC, Phillips T, Hosking JS et al. (2016). Absence of 21st century warming on Antarctic Peninsula consistent with natural variability. Nature 535: 411-415.

Vanhala P, Karhu K, Tuomi M, Björklöf K, Fritze H, Hyvärinen $\mathrm{H}$ et al. (2011). Transplantation of organic surface horizons of boreal soils into warmer regions alters microbiology but not the temperature sensitivity of decomposition. Global Change Biol 17: 538-550.

Wei D, Wang Y, Wang Y. (2015). Considerable methane uptake by alpine grasslands despite the cold climate: in situ measurements on the central Tibetan plateau, 2008-2013. Global Change Biol 21: 777-788.

Wessén E, Söderström M, Stenberg M, Bru D, Hellman M, Welsh A et al. (2011). Spatial distribution of ammoniaoxidizing bacteria and archaea across a 44-hectare farm related to ecosystem functioning. ISME J 5: 1213-1225. 
Yang Y, Fang J, Tang Y, Ji C, Zheng C, He J et al. (2008). Storage, patterns and controls of soil organic carbon in the Tibetan grasslands. Global Change Biol 14: 15921599.

Yang Y, Fang J, Smith P, Tang Y, Chen A, Ji C et al. (2009). Changes in topsoil carbon stock in the Tibetan grasslands between the 1980s and 2004. Global Change Biol 15: 2723-2729.

Yang Y, Wu L, Lin Q, Yuan M, Xu D, Yu H et al. (2013). Responses of the functional structure of soil microbial community to livestock grazing in the Tibetan alpine grassland. Global Change Biol 19: 637-648.
Yang Y, Gao Y, Wang S, Xu D, Yu H, Wu L et al. (2014). The microbial gene diversity along an elevation gradient of the Tibetan grassland. ISME $J$ 8: 430-440.

Yue H, Wang M, Wang S, Gilbert JA, Sun X, Wu L et al. (2015). The microbe-mediated mechanisms affecting topsoil carbon stock in Tibetan grasslands. ISME J 9: 2012-2020.

Zhou JZ, Xue K, Xie JP, Deng Y, Wu LY, Cheng XH et al. (2012). Microbial mediation of carbon-cycle feedbacks to climate warming. Nat Clim Change 2: 106-110.

Supplementary Information accompanies this paper on The ISME Journal website (http://www.nature.com/ismej) 